Portland State University

PDXScholar

World Languages and Literatures Faculty

Publications and Presentations

World Languages and Literatures

$1-2009$

\title{
'Community', Semiotic Flows, and Mediated Contribution to Activity
}

Steven L. Thorne

Portland State University, steven.thorne@pdx.edu

Follow this and additional works at: https://pdxscholar.library.pdx.edu/wll_fac

Part of the Applied Linguistics Commons, and the First and Second Language Acquisition Commons Let us know how access to this document benefits you.

Citation Details

Steven L. Thorne (2009). 'Community', semiotic 88ows, and mediated contribution to activity. Language Teaching, 42, pp 81-94

This Article is brought to you for free and open access. It has been accepted for inclusion in World Languages and Literatures Faculty Publications and Presentations by an authorized administrator of PDXScholar. Please contact us if we can make this document more accessible: pdxscholar@pdx.edu. 


\title{
'Community', semiotic flows, and mediated contribution to activity
}

\author{
Steven L. Thorne The Pennsylvania State University, USA \\ sthorne@psu.edu
}

This article begins with an overview and problematization of the term COMMUNITY through a brief assessment of its history, diverse uses, core attributes, heterogeneous elements, and collocational companions. Following this, I describe demographics and processes associated with collective engagement in digitally mediated environments. Utilizing select alternatives to the term 'community' and incorporating the cultural-historical notions of MEDIATION and ACTIVITY, I then present research describing exogenous influences affecting educational uses of technology in L2 settings, the use of instant messaging and blogging for out-of-class FL interaction at the secondary school level, and a pedagogically focused example of a remixing text posted to an online fan fiction website. I conclude by proposing BRIDGING ACTIVITIES as an approach for connecting the emergent logics of digital vernaculars with the analytics of formal schooling.

\section{Introduction}

In a recent New York Times article, linguist and evolutionary anthropologist Michael Tomasello described the following: 'The remarkable human capacity for cooperation thus seems to have evolved mainly for INTERACTIONS WITHIN THE GROUP. Such group-mindedness is a major cause of strife and suffering in the world today. The solution - more easily said than done is to FIND NEW WAYS TO DEFINE THE GROUP.' (Tomasello 2008, emphasis added)

The purpose of this article is precisely this, to explore new ways to describe, which also inevitably involves defining and reifying, conceptualizations of groups of human beings that cohere in some way. To provide a context for the genesis and orientation of what follows, an early version of this paper was presented as part of a series of lectures that each addressed one of the ' 5 Cs' (i.e., communication, cultures, comparisons, communities, connections) as articulated in the National Standards in Foreign Language Education in the U.S. (National Standards in Foreign Language Education Project (2008), hereafter, the Standards). My assigned topic was COMMUNITY and I took the opportunity to explore the history of the term and its divergent meanings and functions, including a number of related languagefocused frameworks, and proposed alternative formulations. As in the original plenary talk that serves as the partial foundation for this paper, I only briefly address the Standards and

Revised version of a plenary paper presented as part of the University of Wisconsin-Madison Language Institute Lecture Series, 7 February 2006. 
focus primarily on issues relating to 'community' in the context of Internet-mediated contexts and processes through the presentation of three case studies.

\section{Community and the Standards}

The term community in the Standards takes on an assumed common-culture meaning. In the executive summary, for example, it is defined only implicitly as an encouragement for FL learners to 'participate in multilingual communities at home and around the world' and as the context within which students would 'use the language both within and beyond the school setting' (5.1) that may lead to life long learning through 'using the language for personal enjoyment and enrichment' (5.2).

The Standards are encouraging and attempt to orient instructed language education outward, toward life beyond the walls of institutionalized education. The use of community here indexes a warmly persuasive metaphor suggesting affinity and enriching interaction between language-defined groups. In this sense, the Standards employ the term community in one of its most powerful forms, as the civic performance of a proleptic rhetorical move that projects a preferred future. Utilizing the idea of UTOPIAN DIALECTICS, the Marxist human geographer Harvey (2000) has discussed the importance of creating a 'space for thought experiments about alternative possible worlds', but also warns against degenerating into 'the production of unrealizable dreams' (p. 199). The trick to successfully engaging a dialectical movement toward a preferred future, suggests Harvey, is to start with a frank acknowledgement of 'the multiple intersecting material processes that so tightly imprison us in the fine-spun web of contemporary socio-ecological life' (ibid). In the case of FL education in the U.S., such intersecting material imprisonments include, among many others, highstakes testing and washback effects, prescriptivist and accuracy dominated epistemologies and curricula, and in the face of new media literacies, a continued emphasis on increasingly anachronistic text types. The Standards do not substantively address such concerns. Without a fundamental assessment of constraints operating through the social-material conditions of institutionally located language education, the potential impact of the Standards is limited.

\section{Community and its collocates}

Community is a ubiquitous and provocative word, but upon examination of its many formulations and uses, it is fair to wonder what, precisely or even imprecisely, does the term mean? Williams (1976: 75-76) roots the emergence of community into the English language to the 14th century, coming etymologically from the Latin communitatem/communitas. From the 14th century to the present, otherwise divergent meanings tended to be associated with either actual social groups or a particular quality of relationship between people. In the current era, Williams posits a principled distinction between instrumental formations such as society and nation state, and the use of community to represent visceral and engageable units of humanity, the latter a notion mirrored in Tönnies' (2001 [1887]: 222-224) use of 
Gemeinschaft to reflect shared cohesive attributes forged by a 'unity of will' at a level that is more immediate than that of broader society (or Gesellschaft, in Tönnies' dichotomy). In the conclusion to his historical unpacking of community, Williams notes the following: 'What is most important, perhaps, is that unlike all other terms of social organization (state, nation, society, etc.) [community] seems never to be used unfavourably' (1976: 76; italics in original). As Williams suggests, perhaps it is the overwhelmingly positive valence of the term that has so contributed to the proliferation of concepts and attributes that fall under or utilize its name.

Core elements shared across many definitions of community include membership, shared location, shared cultural practices and values, interpersonally meaningful relationships, commitment, reciprocity, collective goods and resources, sense of shared identity, and generally social formations that are durative over time. However, embedded within these generalities are heterogeneous elements and binary oppositions that can make community a problematic and reductive umbrella term. Examples include emphasis on similarity vs. differentiated contribution to collective activity, broad life contexts vs. narrowly shared interests and passions, shared place vs. distribution in space, and categorical elements often attributed from outside the group (race, biological sex, language, sexual orientation) vs. culturally and environmentally contingent processes of ontogenesis and socialization.

To further complicate an understanding of 'community', it often appears with companions. Of the more than twenty commonly used instances I found in use in educationally related research, high frequency examples include DISCOURSE COMMUNITY (Nystrand 1982), SPEECH COMMUNITY (Gumperz 1971; for incisive discussion, see Rampton 1998), IMAGINED COMMUNITY (Anderson 1991), LEARNING COMMUNITY (Roth \& Lee 2006), SENSE OF COMMUNiTy (McMillan \& Chavis 1986), and VIRTUAL GOMMUNiTy (Rheingold 1993). Additional examples include community building, community development, community of interest, and arguably the most frequently used in current research and pedagogy, COMMUNITIES OF PRACTICE (Lave \& Wenger 1991; Wenger 1998).

To alight briefly here, the concept of 'communities of practice' (CoPs) has contributed to many aspects of educational (and other) research and has been largely responsible for defining and popularizing a model of socially situated development involving initially peripheral participants who, over time and in joint interaction with established members, become particular kind of persons (i.e., learn) as a process of participating more centrally in group activity. Generally constructive commentators have noted that the criticality brought by Jean Lave seems to be largely missing in Wenger's (1998) later work, where questions of language, literacy, and power have been somewhat displaced by 'the certainty and oversimplifications of management training' (Barton \& Tusting 2005: 6). In application to education and technology-mediated contexts, Gee (2005) describes other difficulties such as the CoP entailments of membership and belonging, first because of the polysemy of the terms they will mean very different things in different contexts, and second, because membership and belonging may not be relevant constructs to apply to classrooms and online spaces. In language-focused investigations, researchers using critically framed adaptations of CoP have produced insightful findings, while also noting that collective activity among migratory, multilingual and diasporic populations may not readily align with CoP's idealized scenario of long term apprenticeship within stable social formations (e.g., Duff 2007). 
Within a number of language research fields, explicitly linguistic and discursive analyses of language use can be seen to complexify, problematize, and sometimes confound, everyday characterizations of 'community'. Bucholz \& Hall (2004) have critically reviewed and produced research within sociolinguistics and SOCIOCULTURAL LINGUISTICS (the latter a term they currently use to describe their work) that refutes positivist assessments of homogeneous linguistic practices within groups and which further suggests the 'fundamental heterogeneity of even the smallest social group' (475). Other bodies of work have been highly beneficial in charting the ways in which people position themselves and others in material and socialsemiotic worlds. Examples include frameworks articulating conventionalized knowledgelanguage formations and the communicative practices which (re)produce and/or transform them (e.g., Bourdieu 1991); the use of INDEXICALITY to illustrate text-context relations and the ways in which semiotic choice points toward or instantiates norms, roles, group identities, and social orders (e.g., Ochs 1992; Hanks 1996; Silverstein 2003; Blommaert 2005); and within the cultural-historical tradition, a focus on the dialectical tensions between broadly stable MEANINGS of signs and the variable SENSE they catalyze in the contingent dynamics of temporally immediate and in-group semiotic activity (Vološinov 1973; Vygotsky 1987; Thorne \& Lantolf 2007). This listing is partial and overly terse, but it is meant to illustrate the considerable wealth of approaches used to analyze semiotic processes that contribute to the emergence, maintenance, and change over time of group formation and collective identity (i.e., contributors to 'community', however operationalized).

\section{Doing sociality in the digital era}

In his book Bowling Alone, Putnam (2000) described a striking decline in conventional forms of civic and social engagement, providing evidence that from the 1970s, attendance at club meetings had decreased 58\%, family dinners occurred 33\% less frequently, and visits from friends were down $45 \%$. While his research was applauded as empirically sound, a primary critique was that he ignored many newer forms of social capital (i.e., interconnectedness and social networks). Certainly post-2000, one of the primary resources enabling collective engagement is networked communication and information technologies. Over the past two decades, the global Internet user population has grown to approximately 1.4 billion (www.internetworldstats.com). Over this time period, Internet users have extended, refracted and initiated a range of social formations that are in turn mediated by communicative genres and literacy practices that show distinctive features uncharacteristic of conventional print literacies (for discussions, see Thorne \& Payne 2005; Jenkins 2006; Coiro et al. 2008; Sykes, Oskoz \& Thorne 2008; Thorne \& Black 2008).

To list a few examples, in a 2006 survey of 1,852 undergraduates at my home university of Penn State, 93\% were regularly using the social networking environment Facebook, with $62.8 \%$ visiting at least once per day. More broadly, Facebook, self-defined as a 'social utility' is currently available in 15 languages and reports more than 80 million active users with an average of 250,000 new registered users daily since January 2007. Technorati, a portal for a variety of online tools,news, and information, estimated that there were 185,620,000 active blogs as of 11 February 2008. World of Warcraft, currently the most popular massively 
multiplayer online game in the world, claims 10 million paying subscribers (3.5 million of which play on Chinese language servers). And while engagement in many online contexts produces social ontologies with identifiably specific characteristics, it is increasingly salient that online activities interpenetrate with other realms of life activity at many levels. To take two personal examples, (1) individuals see one another in face-to-face and online computer game contexts and semiotic styles associated with each realm flow back and forth between these systems of otherwise culturally and linguistically distinctive activity; (2) ideas from an academic journal article propagate out across various media, from the article into the blogosphere, then into a newswire press release, which in turn comes back to the author of the journal article via email from an acquaintance. It is an increasingly common experience for much of the networked world, therefore, that everyday constructions of social identity, which are always bound to multiple individuals, groups, and activity systems, are now mediated by the use of Internet communication tools, web environments, and online gaming spaces. In this sense, new media and communication technologies enable participants to develop and modify text and media presentations of self and collective identity, forming what Thurlow \& McKay (2003: 98) have described as 'the internet as learning and lifestyle resource'.

\section{Case study examples of Internet mediated L2 use}

L2 education can (and should) involve wondrous processes of guided discovery where a ladle is dipped into a vast ocean of foreign signifiers which then can be closely examined for their structure, meanings and potential uses. This said, FL classes in particular, due in good part to their isolation from ready contact with the focus language beyond the class setting, are often bounded contexts providing limited opportunities for committed and consequential communicative engagement (for exceptions, see Thorne 2006 and contributions to Belz \& Thorne 2006, describing interculturally oriented L2 education models). Each of the cases below reflects cross-context movement and mappings that suggest resources relevant to language education. I begin with studies that are directly linked to instructed L2 education and then describe a third case that extends out into the digital commons.

\subsection{Cultures-of-use and learning in exogenous activity systems}

Much of my research on Internet use in L2 education draws from and contributes to theoretical treatments of MEDIATION and ACTIVITY SYSTEM analysis (Thorne 2000, 2003, 2004, 2005; see also Engeström 2001; Lantolf \& Thorne 2006). The earlier work illustrated that students' discursive framing of Internet-mediated L2 activity was strongly influenced not by standard conventions of academic discourse that often hold sway in instructed language learning settings, but by their prior and ongoing participation in exogenous online speech communities and environments. The key to understanding why this should be the case came through a focus on artifact mediation, that Internet communication tools, like all human creations, are cultural tools (e.g., Cole 1996; Nardi 1996) which carry interactional, ideational, and relational associations, preferred and correspondingly dispreferred uses, and expectations 
of genre-specific communicative activity. Correspondingly, mediated communicative practice is informed by distinctive CULTURES-OF-USE - that is, in interaction with immediate contextual conditions, 'the historically sedimented characteristics that accrue to a [computer-mediatedcommunication] tool from its everyday use' (Thorne 2003: 40; see also Thorne \& Black 2008).

In application to instructed L2 contexts, the cultures-of-use notion reminds us that technologies are historically structured and structuring forms of culture which can influence whether certain desired (from the instructor's point of view) interactions are even possible. To illustrate this point, in the spring of 2002, I helped to organize an Internet-mediated intercultural exchange between students studying French as a foreign language in the U.S. and students studying English in France. Email was selected as the primary communication tool. Surprisingly (to the designers of the intervention), a significant number of the American students refused to engage in age-peer communication using email. For these students, email was used exclusively for vertical communication across generational and power lines (e.g., with teachers, parents, employers) but was not suitable for age-peer relationship building, which was the core pedagogical thrust of the project. A few dissatisfied students self-initiated a migration of their correspondence to instant messenger (IM) and the effect was enormous. A focal student reported, and provided transcripts to illustrate, daily IM conversations with her French key-pal, some of which extended to multiple hours of mixed FrenchEnglish communication (Thorne 2003). The obvious variable in this instance is selection of communication tool. I wish to underscore, however, that while Internet communication tools carry the historical residua of their use across time, patterns of past use inform, but do not determine, present and future activity. Rather, the cultures-of-use framework for addressing research and pedagogical innovation in Internet environments provides an axis along which to perceive and address issues of genre conflict, variation, and alignment (see also Kramsch \& Thorne 2002).

\subsection{Stylization, 'shuttling', and centrifugal flows}

I report here on an ongoing research project with American high school students enrolled in an advanced placement (or AP, a designation reflecting university level instruction) Spanish FL course. In collaboration with me and with the goal of leveraging positive associations many of her students had with Internet communication tools, Dana Webber, the course instructor, integrated weekly blog assignments and out-of-class instant messenger (IM) use into the course activities. Inspired by Vološinov's (1973: 123) notion that it is 'solely through the utterance [use] that LANGUAGE makes contact with COMMUNICATION, is imbued with its vital power, and becomes a reality' (emphases added), our research focus is to examine the relations between in- and out-of-school technology use and to attempt to engineer conditions that would make possible a shift from FL learning as a rote process of acquisition and toward envisaging language as a resource for meaningful social action and relationship building.

Students in the course were provided with personal blog sites, given open or topic driven writing assignments, and were responsible for commenting on three of their peers' blog posts on a weekly basis. The students used IM for Spanish language interaction with interlocutors of their choice and turned in transcripts of the sessions as evidence of completing the assignment. 
At the point of this writing, 28 students have participated in approximately 45-minute followup ethnographic interviews during which they were asked to talk about regular uses of information and communication technologies, their social uses of instant messaging, blogging, and online gaming activities, and to reflect on the uses of blogs and IM for learning Spanish. While we have encouraging preliminary analyses of students' written production as well as standardized assessment measures showing significant Spanish language development (for example, the standardized Advanced Placement exam average score for this cohort increased to 3.73 (of 5 maximum) from 3.2 in the prior year's cohort), the issues I focus on here involve dynamics between in- and out-of-class communication and are based on data from the interviews with students.

In terms of blog usage, all participants had a strong preference for blogging versus traditional weekly essays. Students reported that they frequently looked back over their own and others' earlier blog posts, and all self-assessed as having noticed significant progress in their writing over time. In interviews, students reported the following: 'my writing has become more fluid', 'my sentences don't stand alone - I write in paragraphs now', and 'I use more tenses and make an effort to incorporate whatever we're doing in class, subjunctive, conditional, whatever, into my blogs'. Analyzing interrelations between academic and socialpersonal presentations of self, we found that blog use formed an interstitial communication space where both academic and nonacademic discursive features were articulated through personally relevant expression, in essence that students were writing both to fulfill a class requirement while also writing to and for one another. This hoped-for outcome was confirmed in the interviews:

Student 1: I think [blogging] is helpful in a way, because you kind of find that common ground between your teacher and your peers. You think about how you're gonna direct and drive your conversation, like you wanna make sure that, you know, your teacher understands how you feel, at the same time you wanna make sure that your peers know what you feel, and it's just different because your peers might be going through the same thing, but your teacher might not necessarily understand what you're going through, so you wanna make sure that they both understand. (italics added for emphasis)

In this excerpt, the student explicitly states a sense of agency and self-efficacy, 'you think about how you're gonna direct and drive your conversation'. She also indicates a clear awareness of the need to speak to multiple audiences, 'you wanna make sure that [students and the teacher] both understand'. The student's repeated emphasis on her intent to successfully represent her FEELINGS in L2 writing suggests that her primary concern is to establish and maintain intersubjectivity with her teacher and classmates.

Most surprising to us was that a number of students reported cross-posting Spanish language entries to their personal blog spaces and, conversely, translating into Spanish some of their writing that had initially been posted to their personal sites. Canagarajah (2006) describes such authorial choices with the term SHUTTLING, where individuals move between defined social-textual conventions and make strategic use of semiotic and narrative resources, sometimes across and sometimes within specific languages and genres, to achieve personally relevant intentions. To paraphrase Canagarajah (2006: 602-603), writing is not merely constitutive; it is also performative, context-transforming, and acts as an affordance for the ongoing negotiation of voice and presentation of self. This is an especially pertinent point given 
the importance of blogging to the social lives of many young adults. In contrast to my earlier work that described the CENTRIPETAL flow of exogenous online communicative practices into education (see section 5.1 above), here we see CENTRIFUGAL flows of textual practices that began in instructed settings but which also serve additional purposes in other domains. This bi-directional and bi-lingual movement and transformation of texts is encouraging for it demonstrates discrete instances of use value for students emerging from instructed FL activity; it also suggests an overarching semiotic ecology that is inclusive of both schooling and students' broader life contexts.

Speaking to this latter point, the course participants also described what I have termed a LATE MODERN COMMUNICATIVE AESTHETIC (Thorne 2000) that appears to operate above the level of linguistic variety.

Student 2: I've noticed that people sort of find their own style of writing blogs or IM and you sort of adopt that as you go whether it be in English or Spanish.

Student 3: You have Spanish IMs, so being clever and using words well and you know how it is ... you have to make up a personality using words, so you have to do that in Spanish.

Student 4: When I come into class, I would say hola Señora, and sometimes I find myself saying that in my Physics class, you know, ... even online, I'd randomly [IM] my friends in Spanish and I feel like I'm really learning and it's just, like, becoming more natural.

These student comments suggest that they perceive Spanish as a viable language for performing identity work. At the same time, they casually deemphasize the particularities of any specific language and instead focus on doing things WITH LANGUAGE, such as 'finding a style', 'being clever and using words well', and 'making up a personality'. Rampton (2006) has described LANGUAGE CROSSING and STYLIZATION as AGENTIVE PRACTICES (see also Khan 2007) in which young people recruit semiotic resources and deploy them for their social meaning potentials. Here, we see glimmers of a ritualized and positively valenced form of crossing in Student 4's use of Spanish in her Physics class. Stylization, the strategic use of socially salient features of a linguistic variety for pragmatic purposes, appears throughout the interview, blog, and IM data as a resource for solidarity building and alignment, production of the self as a multilingual and witty interlocutor, and to serve a variety of ritualized pragmatic functions. In his model of EXPANSIVE LEARNING, Engeström (2001) describes a broadening of the object of activity (the overall goal or orientation of activity) through the collaborative creation and internalization of new mediational resources. For many of these students, the use of blogs and IM seems to have helped to catalyze a new goal associated with Spanish language learning, that of figuring out how to become a viable, interesting person with Spanish as a resource for doing so.

\subsection{Participatory genre and the case of a remixing (fan fiction) text}

Some years ago, Erickson (1997), a digital cultures researcher and designer, proposed the notion of PARTICIPATORY GENRE as a replacement for the analytic use of community in research on computer-mediated text-based social interaction. Erickson's suggestion is attractive for two reasons: first, for its fronting of the systematic ways that language functions 
in and co-produces social and cultural contexts (genre), and second, because it emphasizes participation within a framework that links historically developed activity systems with the grounded, discursive-material instantiation of communicative practice. Additionally, the notion of participatory genre emphasizes speaking subjects who shape and transform the genres in which they participate but who are also influenced by its regularities, selection biases, and performative conventions.

Represented in venues such as Youtube.com and popular culture websites, blogs and wikis, a wide variety of participatory genre practices have emerged with linkages to texts as diverse as Japan-inspired anime and manga, and the Harry Potter books and Lord of the Rings. Lankshear \& Knobel (2007) have described these remixing literacy practices and make the following observations:

Even the concept of 'text' as understood in conventional print terms becomes a hazy concept when considering the enormous array of expressive media now available to everyday folk. Diverse practices of 'remixing' - where a range of original materials are copied, cut, spliced, edited, reworked, and mixed into a new creation - have become highly popular in part because of the quality of product it is possible for 'ordinary people' to achieve. (Lankshear \& Knobel 2007: 8)

I present here a few examples of textual forms of remixing related to the English and Japanese language example I describe below:

- Scanlations (a portmanteau of scan and translation): Anime texts are digitally scanned, then the original Japanese language text is replaced with English or other language translations.

- FAnsub (fan-subtitled): The original Japanese language is maintained while subtitles are added to make the work accessible to speakers of other languages.

- Fan fiction: Derivative texts in which fans draw from popular media to support the composition of their own stories.

In a series of insightful papers and a book length treatment describing fan fiction, Black (2005, 2006, 2008) describes enthusiasts of various popular cultural media who build from existing literary tropes, settings, characters, and storylines to construct their own fictional narratives. In producing a fan fiction text, authors may remix media, combine or flout genre conventions, and use multiple languages and cultural themes. As an example of a pedagogically interesting mixed language composition, I briefly discuss a fan fiction text based on Naruto, initially a Japanese MANGA series that has expanded to include ANIME and video game media. The complete story is available on www.fanfiction.net. ${ }^{1}$

The protagonist, Naruto Uzumaki, is described as a 'loud, hyperactive, unpredictable, adolescent ninja who constantly searches for recognition and aspires to become a Hokage, the ninja in his village that is acknowledged as the leader and the strongest of all' (www.wikipedia.org). Titled 'The importance of eloquence', the fan fiction text based on this character is written in English, faithful to the manga storyline, and attentive to Japanese

\footnotetext{
${ }^{1}$ Find the story at http://www.fanfiction.net/s/3160888/1/The_Importance_of_Eloquence.
} 
cultural dynamics and hierarchies. The story was composed so that subtle flouting of Japanese honorific language propels the story line and the author provides a preface sentence challenging readers to attend specifically to honorific terms in the story. As an addendum, the author provides 'notes' that instruct readers in general Japanese honorifics (nineteen are defined) and further explains the particular instances of pragmatic flouting that drive the narrative. In a reflexive and self-deprecating style, the author concludes that $\mathrm{s} / \mathrm{he}$ is only a 'crappy mangasha' while Kishimoto, the Japanese manga artist responsible for the Naruto series, is an 'accomplished mangaka'. The author is doing two things here: illustrating correct uses of the suffixes $-k a$ and $-s h a /-j a$, and utilizing Japanese language morphology to creatively play on the genre of copyright disclaimers that often accompany fan fiction texts posted to publicly available websites. Finally, it is worth recalling that this text was produced as a leisure activity and is one of a large number of fan fictions produced by the author.

Remixing practices in the service of language learning align beautifully with Bakhtin's (1986: 89) formulation that 'we acquire language through a "process of assimilation" - more or less creative - of others' words (and not the words of a language)'. To attain nuanced levels of symbolic competence (in the sense of Kramsch 2006), development requires production (Swain 2000), albeit in the late modern sense of strategically assembled semiotic repertoires that in many cases, such as the Naruto-inspired text above, may include the use of two or more linguistic varieties.

Drawing upon Vygotskian developmental theory, fan fiction sites might be described as vast constellations of artifacts and human resources supporting processes associated with the ZONE OF PROXIMAL DEVELOPMENT (ZPD). The ZPD is defined as the difference between what an individual (or group) can accomplish independently and what the same individual (or group), through imitation and contingently provided assistance, can accomplish in joint activity (e.g., Vygotsky 1978; Kinginger 2002; Lantolf \& Thorne 2006). Development involves actively resolving contradictions through a process of changes in the locus of control necessary to regulate thinking. Within the theory, object-regulation describes instances when artifacts in the environment afford or make possible cognition/activity. In the context of authoring fan fiction, object-regulation could include the availability of existing storylines, characters, model texts, and awareness of genre conventions. Other-regulation describes mediation by people, such as would be present through vibrant fan fiction reviewing cultures which themselves form a distinctive variety of participatory genre. Self-regulated individuals, for whom external assistance is largely unnecessary because external forms of mediation have been internalized, serve as models and mentors.

In application to language learning, fan fiction authors have the potential support, through artifacts and human mediators, to assemble complex texts based on personally interesting fictional worlds. And perhaps as importantly, they have a reason to do so (an attentive audience and peers providing feedback) and visceral evidence (the texts they author) that they are contributing to a greater enterprise through their participation. In application to fan fiction sites and other language-centric arenas of human conduct, the concept of participatory genre helps to unite cultural-historical mediation, such as pre-existing texts, tropes, and conventions, with the emergent and transformative practice of MEDIATED CONTRIBUTION TO COLLECTIVE ACTIVITY. 


\section{Bridging between divergent systems of culturally organized activity}

This discussion has argued that what occurs online and outside of school involves extended periods of language socialization, adaptation, and creative semiotic work that illustrate vibrant modality and interlocutor specific communicative practices. With this being the case, it is troublesome that new media literacies remain largely unacknowledged within instructed L2 contexts and curricula, or worse, are treated as stigmatized varieties that have no place in the classroom. In an era in which mediated communication constitutes an important or even primary modality for social, recreational, and professional life, it is ironic that mastery of highfrequency and high-stakes mediated genres of communication have not been systematically included among the explicit goals of L2 educational practice.

Compelled by what we see as a primary contradiction between the critical importance of high stakes power genres (i.e., formal registers) and the emergent-contingent logics of digital vernaculars, a colleague and I (Thorne \& Reinhardt 2008) have designed a pedagogical framework called BRIDGING ACTIVITIES. We begin by establishing the need for language- and genre-focused activities that attend to the shifting social practices and emerging literacies associated with digital media. Grounded in principles of language awareness and the concept of multiliteracies (e.g., New London Group 1996; Cope \& Kalantzis 2000), bridging activities center on teacher-guided exploration and analysis of student-selected or student-created digital vernacular texts originating in Web 2.0 and other technologies/practices such as instant messaging, blogs and wikis, remixing, and multiplayer online gaming. Application of the model includes an iterative implementation cycle of (1) observation and collection, (2) guided exploration and analysis, and (3) creation and participation. As a form of transparent pedagogy, stages of the implementation cycle can be used to highlight 'community'-related dynamics and processes, such as those of interactivity system flow, stylization and crossing, shuttling, and participatory genre described above.

In sum, the bridging activities approach couples students' digital vernacular interests with instructor guidance to explore structural, functional, and pragmatic dimensions of living language use. The immediate instructional objective is to strengthen the ecological relations between language practices and identity dispositions developed within both instructional L2 settings and the plurilingual world outside of school. The superordinate goal is to foster critical awareness of the anatomy and functional organization of a wide range of communicative practices relating to both digital and print literacy conventions. In turn, this will support 'just-in-time' learning of future linguistic repertoires through careful attention to language practices emergent of the local situation as well as attunement to resources that might be made relevant from exogenous systems of activity. Ultimately, the aim is not merely to gain the mastery necessary to reproduce language and culture practices, but also to be able to contribute to forging new ones in the crucible that forms everyday communicative interaction.

\section{Coda}

In the closing moments of the plenary address that preceded the writing of this article, I asked the rhetorical question, 'Will I continue to use the term and loose confederation of referents 
and sentiments indexed by the word "community"?' My response was a resounding 'You bet!' As I have attempted to illustrate throughout this discussion, while 'community' is minimally a polysemous, and potentially a reductive, unit of social analysis, it is also an evocative term with an illocutionary force of pronouncement that has the potential to galvanize individuals into collective action. To add to Williams' (1976: 76) exegesis of the term, community is a 'warmly persuasive word'. In the Standards document briefly discussed at the start of the paper, the encouragement to interact with domestic communities of speakers of different languages, and further to view multilingual competence as a resource for international personal and professional activity, serves the potentially useful function of indirectly contesting the doxa of xenephobia that runs just beneath America's 'melting pot' mythology. As a research tool for descriptive and referential purposes, however, the term community, with or without additional descriptors, continues to bring with it problematic entailments of homogeneity and similarity. Rampton (1998: 26) has described the challenge this way: 'The manner and extent to which community-as-ideal insists on uniformity or builds on social difference is certain to continue as a crucial political and analytic issue'.

The comments by Michael Tomasello that opened this article remind us that 'new ways to define the group' may push against phylogenetically developed propensities for in-group cooperation and out-group fear and aggression. Vygotsky's ideas offer some hope in regard to this issue. His theory of development emphasizes that ontogenesis is a process through which progressive internalization of sociohistorically formed tools and practices afford humans the capacity to organize and control their biology. While we cannot readily change our biology, we can invent new cultural tools, and to some degree, we can make the conscious choice to attempt to live life through them.

\section{Acknowledgements}

I would like to express my appreciation to the University of Wisconsin-Madison Language Institute for providing the forum within which to present and interactively discuss the ideas that came to form this article. Additionally, I am indebted to Penn State's Center for Advanced Language Proficiency Education and Research (CALPER) for technology support for some of the projects reported here. I am also grateful to Rebecca Black, James Lantolf, and anonymous reviewers for insightful and encouraging feedback on earlier versions of this article.

\section{References}

Anderson, B. (1991). Imagined communities. New York: Verso.

Bakhtin, M. M. (1986). Speech genres and other late essays. Austin, TX: University of Texas Press.

Barton, D. \& K. Tusting (2005). Introduction. In Barton \& Tusting (eds.), 1-13.

Barton, D. \& K. Tusting (eds.) (2005a). Beyond communities of practice. New York: Cambridge.

Belz, J. \& S. L. Thorne (eds.) (2006). Internet-mediated intercultural foreign language education. Boston, MA: Heinle.

Black, R. W. (2005). Access and affiliation: The literacy and composition practices of English language learners in an online fanfiction community. Fournal of Adolescent \& Adult Literacy 49, 118-128.

Black, R. W. (2006). Language, culture, and identity in online fanfiction. E-learning 3, 170-184. 
Black, R. W. (2008). Adolescents and online fan fiction. New York: Peter Lang.

Blommaert, J. (2005). Discourse. Cambridge: Cambridge University Press.

Bourdieu, P. (1991). Language and symbolic power. Cambridge, MA: Harvard University Press.

Bucholtz, M. \& K. Hall (2004). Theorizing identity in language and sexuality research. Language in Society 33, 469-515.

Canagarajah, S. (2006). Toward a writing pedagogy of shuttling between language: Learning from multilingual writers. College English 68, 589-604.

Coiro, J., M. Knobel, C. Lankshear \& D. Leu (eds.) (2008). Handbook of research on new literacies. Mahwah, NJ: Lawrence Erlbaum.

Cole, M. (1996). Cultural psychology: A once and future discipline. Cambridge, MA: Belknapp Press.

Cope, B. \& M. Kalantzis (eds.) (2000). Multiliteracies: Literacy learning and the design of social futures. New York: Routledge.

Duff, P. (2007). Second language socialization as sociocultural theory: Insights and issues. Language Teaching 40, 309-319.

Engeström, Y. (2001). Expansive learning at work: Toward an activity theoretical reconceptualization. Fournal of Education \& Work 14, 133-156.

Erickson, T. (1997). Social interaction on the net: Virtual community as participatory genre. Proceedings of the Thirtieth Hawaii International Conference on Systems Science (vol. 6). Los Alamitos, CA: IEEE Computer Society Press, 23-30.

Gee, P. (2005). Semiotic social spaces and affinity spaces: From the Age of Mythology to today's schools. In Barton \& Tusting (eds.), 214-232.

Gumperz, J. (1971). Language in social groups. Stanford, CA: Stanford University Press.

Hanks, W. (1996). Language and communicative practice. Boulder, CO: Westview Press.

Harvey, D. (2000). Spaces of hope. Berkeley, CA: University of California Press.

Jenkins, H. (2006). Convergence culture: Where old and new media collide. New York: New York University Press.

Khan, A. (2007). Good to think? Creolization, optimism, and agency. Current Anthropology 48, 653-673.

Kinginger, C. (2002). Defining the zone of proximal development in US foreign language education. Applied Linguistics 23, 240-261.

Kramsch, C. (2006). From communicative competence to symbolic competence. The Modern Language Fournal 90, 249-252.

Kramsch, C. \& S. L. Thorne (2002). Foreign language learning as global communicative practice. In D. Block \& D. Cameron (eds.), Globalization and language teaching. London: Routledge, 83-100.

Lankshear, C. \& M. Knobel (2007). Sampling 'the new' in new literacies. In M. Knobel \& C. Lankshear (eds.), A new literacies sampler. New York: Peter Lang, 1-24.

Lantolf,J. P. \& S. L. Thorne (2006). Sociocultural theory and the sociogenesis of second language development. New York: Oxford University Press.

Lave, J. \& E. Wenger (1991). Situated learning: Legitimate peripheral participation. Cambridge: Cambridge University Press.

McMillan, D. W. \& D. M. Chavis (1986). Sense of community: A definition and theory. Fournal of Community Psychology 14, 6-23.

Nardi, B. (ed.) (1996). Context and consciousness: Activity theory and human-computer interaction. Cambridge, MA: MIT Press.

National Standards in Foreign Language Education Project. (2008). Standards for foreign language learning in the 21st century. Yonkers, NY: Allen Press.

New London Group. (1996). A pedagogy of multiliteracies. Harvard Educational Review 66, 60-92.

Nystrand, M. (1982). What writers know: The language, process, and structure of written discourse. New York: Academic.

Ochs, E. (1992). Indexing gender. In A. Duranti \& G. Goodwin (eds.), Rethinking context: Language as an interactive phenomenon. Cambridge: Cambridge University Press, 335-358.

Putnam, R. D. (2000). Bowling alone: The collapse and revival of American community. New York: Simon and Schuster.

Rampton, B. (1998). Speech community. In J. Vershueren, J. O. Östman, J. Blommaert \& C. Bulcaen (eds.), Handbook of pragmatics. Amsterdam: John Benjamins, 1-34.

Rampton, B. (2006). Language in late modernity: Interaction in an urban school. Cambridge: Cambridge University Press.

Rheingold, H. (1993). The virtual community. New York: Addison-Wesley. 
Roth, W.-M. \& Y.-J. Lee (2006). Contradictions in theorising and implementing communities in education. Educational Research Review 1, 27-40.

Silverstein, M. (2003). Indexical order and the dialectics of sociolinguistic life. Language and Communication 23, 193-229.

Swain, M. (2000). The output hypothesis and beyond: Mediating acquisition through collaborative dialogue. In J. Lantolf (ed.), Sociocultural theory and second language acquisition. Oxford: Oxford University Press, 97-114.

Sykes, J., Oskoz, A. \& S. L. Thorne (2008). Web 2.0, synthetic immersive environments, and mobile resources for language education. CALICO Journal 25, 528-546.

Thorne, S. L. (2000). Beyond bounded activity systems: Heterogeneous cultures in instructional uses of persistent conversation. Proceedings of the Thirty-third Annual Hawaii International Conference on System Sciences (HICSS-33). Los Alamitos, CA: IEEE Computer Society Press, 1-10.

Thorne, S. L. (2003). Artifacts and cultures-of-use in intercultural communication. Language Learning \& Technology 7, 38-67.

Thorne, S. L. (2004). Cultural historical activity theory and the object of innovation. In K. van Esch \& O. St. John, (eds.). New insights into foreign language learning and teaching. Frankfurt: Peter Lang, 51-70.

Thorne, S. L. (2005). Epistemology, politics, and ethics in sociocultural theory. Modern Language fournal 89, 393-409.

Thorne, S. L. (2006). Pedagogical and praxiological lessons from Internet-mediated intercultural foreign language education research. In J. Belz \& S. L. Thorne (eds.), Internet-mediated intercultural foreign language education. Boston, MA: Thomson Heinle Publishers, 2-30.

Thorne, S. L. \& R. W. Black (2008). Language and literacy development in computer-mediated contexts and communities. Annual Review of Applied Linguistics 27, 133-160.

Thorne, S. L. \& J. P. Lantolf (2007). A linguistics of communicative activity. In S. Makoni \& A. Pennycook (eds.), Disinventing and reconstituting languages. Clevedon: Multilingual Matters, 170-195.

Thorne, S. L. \& J. S. Payne (2005). Evolutionary trajectories, Internet-mediated expression, and language education. CALICO Fournal 22, 371-397.

Thorne, S. L. \& J. Reinhardt (2008). 'Bridging activities', new media literacies and advanced foreign language proficiency. CALICO Journal 25, 558-572.

Thurlow, C. \& S. McKay (2003). Profiling 'new' communication technologies in adolescence. fournal of Language and Social Psychology 22, 94-103.

Tomasello, M. (2008). How are humans unique? New York Times, 26 May 2008.

Tönnies, F. (2001 [1887]). Community and civil society (Jose Harris, ed.). Cambridge: Cambridge University Press.

Vološinov, V. N. (1973). Marxism and the philosophy of language. New York: Seminar Press.

Vygotsky, L. S. (1978). Mind in society: The development of higher psychological processes (M. Cole, V. JohnSteiner, S. Scribner \& E. Souberman, eds.). Cambridge, MA.: Harvard University Press.

Vygotsky, L. S. (1987). The collected works of L. S. Vygotsky (vol. 1): Problems of general psychology: Including the volume Thinking and speech (R. W. Reiber \& A. S. Carton, eds.). New York: Plenum Press.

Wenger, E. (1998). Communities of practice: Learning, meaning, and identity. Cambridge: Cambridge University Press.

Williams, R. (1976). Key words. New York: Oxford University Press.

Steven L. Thorne is Assistant Professor in the Department of Applied Linguistics and Associate Director of the Center for Language Acquisition at the Pennsylvania State University. His interests include new media literacies and projects that engage cultural-historical activity theory, contextual traditions of language analysis, and usage-based approaches to language development. His books include Sociocultural theory and the genesis of second language development (co-authored with James Lantolf; Oxford University Press, 2006) and Internet-mediated intercultural foreign language education (co-edited with Julie Belz; Heinle, 2006). 